\title{
Utilization of Oil Properties to Develop a Spreading Rate Regression Model for Nigerian Crude Oil
}

\author{
Adeola Grace Olugbenga1, Muibat Diekola Yahya1, Mohammed Umar Garba1, \\ Abubakar Mohammed ${ }^{2}$ \\ ${ }^{1}$ Department of Chemical Engineering, Federal University of Technology Minna, Minna, Nigeria \\ ${ }^{2}$ Materials and Engineering Research Institute, Sheffield Hallam University, Sheffield, United Kingdom \\ Email: grace.adeola@futminna.edu.ng, umar.garba@futminna.edu.ng, muibat.yahya@futminna.edu.ng, \\ mohammed_mcjesus@yahoo.com
}

How to cite this paper: Olugbenga, A.G., Yahya, M.D., Garba, M.U. and Mohammed, A. (2020) Utilization of Oil Properties to Develop a Spreading Rate Regression Model for Nigerian Crude Oil. Advances in Chemical Engineering and Science, 10, 332-342. https://doi.org/10.4236/aces.2020.104021

Received: July 25, 2020

Accepted: September 15, 2020

Published: September 18, 2020

Copyright $\odot 2020$ by author(s) and Scientific Research Publishing Inc. This work is licensed under the Creative Commons Attribution International License (CC BY 4.0).

http://creativecommons.org/licenses/by/4.0/

\begin{abstract}
The target of this study is to develop a spreading rate regression model capable of predicting rate of spread of Nigerian crude oil spills on water. The major factors responsible for spreading rate of crude oil on water were considered, namely surface tension, viscosity, and specific gravity/American Petroleum Institute degree $\left({ }^{0} \mathrm{API}\right)$, all at specified temperature values. The surface tension, viscosity and density parameters were interactively measured under controlled factorial analysis. The spreading rate of each crude oil was determined by artificially spilling them on laboratory calm/stagnant water in a rectangular tank and their averages were also computed. These averages were used to develop a regression model equation for spreading rate. The model developed indicated that an average spreading rate was $3.3528 \mathrm{~cm} / \mathrm{s}$ at $37.5^{\circ} \mathrm{C}$ and the predictive regression model is evaluated with the interactions of specific gravity, viscosity and surface tension. It is convenient to state that the model will predict the spread rate of crude oils which possess imputed physicochemical properties having pour point averaged $15.5^{\circ} \mathrm{C}$ on calm seawater.
\end{abstract}

\section{Keywords}

Specific Gravity, Viscosity, Surface Tension, Spreading Rate, Model

\section{Introduction}

Exploration for oil in Nigeria began as long as 1908, although the surveying using modern techniques was not carried out until 1937 and there was not a cessation of operations during the 1939 to 1945 war [1]. Far back as these early days till date it has been a stiff challenge to provide the behaviour or fate of crude oil 
on Nigerian water. It is obvious that the interaction of the oil properties with the water temperature dictates the changes that oil attains at spillage. This provides an extent of how oil is affected by alterations in atmospheric and water temperature as it moves through the marine environment. Thus an update on the extent of spared whenever oil spill is relevant to engineers, oil and gas personnel, industrial managers, researchers and spill responders. The first commercial accumulation of light oil was discovered at Olobiri in 1955 [1]. The output from Oloibiri's discovery was soon followed by a number of others in the Port Harcourt and Afarm areas, of which Imo River, Bomu, Umechem Koro proved to be the most prolific. Other onshore discoveries were made in the Mid-west region for example, at Olomoro and Uzera. A number of important off shore fields were also discovered for example, Okan, Okubie. In this part of West Africa, the slope of the continental shelf is very gentle, allowing oil seepage into the water bodies, so that a large area of shallow water is accessible for exploration [2] and very prune to oil spillage. Naturally oil escapes from reservoir and seeps into the water in the Niger Delta region of Nigeria. This has posed a threat to the surrounding lives and environment has become unconducive for both farming and sea activities. Besides natural oil seepage into the water bodies, accidental oil spillage is common. Last decade the report on oil spillage was common for example [3] the same occurrence of spillage continues to the last decade For example, [4] Shell Petroleum Development Company of Nigeria (SPDC) was affected by the oil spill on March 22, 2013 at the Nembe Creek in Niger Delta. Up till date the activities that lead to spillage have not ceased, for example [5]. Subsequently, production was affected due to the pollution in the Nembe Creek Truck Line (NCTL) because of the evacuation exercise of some bunkering points on pipeline vandalization by oil thieves in the region. Oil production is usually shut down in order to depressurize and isolate the line. In Nigeria, this is the only safe way to manipulate the line. On the same Nembe Creek, within the last one year, 157 bunkering points were reported to have been removed and 116 were reported to be licking at the SPDC exploration. It is also common that an upsurge in pipe destruction has often resulted into a devastating oil pollution as well as a huge loss of thousands of barrels year in year out. Since accidents happen without an occurrence [6] it has become apparently necessary to obtain the spread of oil which can enhance design of an emergency responds to arrest spillage which in the long run is economical thus arrest the devastating effect on aquatic lives as well as the health of operational personnel. Highlighted here is the availability of predictable model for both immediate, intermediate and future spread rate of oil spill. Therefore to plan effectively for any responds to oil spillage, it is primarily necessary to be able to locate the extent of the spilled oil as well as define the oil's viscosity and dispersion which are spread rate dependent. Both the oil properties and environmental conditions are required to design the steps taken to achieve an end results of the spreading rate of oil on water [7]. While data from the surrounding environment depends completely on the prevailing condition at in-situ and time of spread. The oil properties are completely relying on oil composition 
and chemical constituent. This work is targeted at predicting the spreading rate of oil on calm water with zero assumption for turbulence and ocean current. Sea turbulence and ocean current are however vital but they are better computed for modelling dispersion. If they must be used in the spreading rate models, a steady state assumption is first preferred to precede the eddy activity assumptions in models defining the fate of oil on sea water [8]. Besides the spreading and dispersion of oil, the fate of oil can equally be determined by evaporation, sedimentation, emulsification and biodegradation [9] [10] At present it has not been possible to determine the location, extent and thickness and type of oil pollutant using just one single model for the Nigerian crude oil.

$$
R(t)=\left[[11.23-1.07]\left(\frac{S+2_{\gamma_{0}}-1.285\left(\gamma_{w} \gamma_{o}\right)^{\frac{1}{2}}}{0.05539\left(\gamma_{w} \gamma_{o}\right)^{\frac{1}{2}}}\right)+\frac{1}{3} V\right]
$$

[11] obtained the Equation (1) as the new comprehensive empirical model for the prediction of the spreading of a finite quantity of oil spill on a placid aquatic medium. Where $\gamma$ is the free energy per unit area of new surface. Dimensionally, this is $\mathrm{erg} / \mathrm{cm}^{2}$, dyne $/ \mathrm{cm}, \mathrm{nN} / \mathrm{m}$ or $\mathrm{g} / \mathrm{s}^{2}$. Component $\mathrm{w}$ constitute the substrate (water), $o$ the spreading oil $\mathrm{S}$ is the surface tension. $V$ is the velocity.

Five clean-up strategies that frequently receive consideration include: mechanical clean-up or recovery, burning, bioremediation, treatment with chemical dispersants, and adsorption. The morphology of the slick near its leading edge and over the entire covered area in the terminal stages of spreading is strongly affected by surface tension forces [7]. Surfactant may influence on crude oil tension [12].

Another critical factor that affects the spreading rate of spilled oil is temperature which invariably affects viscosity of the spilled oil [13], the viscosity of oil is influenced by the ambient temperature, and that is, if it is warm the spilled oil will be less viscous so it will spread faster.

The surface properties in particular, surface and interfacial tensions of the water body themselves are equally of key importance. Such information is crucial for determining the actual or potential pollution pathways of crude oil spills. The micro-layer surfactants present in sea water (unlike artificial sea water) originate from several sources: petroleum deposits, biological activity of plankton, terrestrial material or atmospheric precipitation [14], and can affect the way oil spreads on water. In addition, the presence of surfactants in both the aqueous and oil phases can lead to interfacial tension gradients giving rise to "Marangoni" stresses [15] that could also initiate and drive the spreading process [16]. An understanding of the structure of liquids adjacent to other surfaces, and of how surface wettability is governed by interfacial forces or phenomena, is important in many technological, industrial, chemical and biological situations [17] especially in oil spill and remediation. Polymeric surfactants which can increase water viscosity and as well decrease interfacial tension are reported for water and crude oil interactions [18]. 
The spreading rate of oil on water is yet to be fully understood. For the Nigeria crude oil no current report has been provide to predict the spreading rate despite the complicated scenario of biological fishing activities in the sites of spread which confirms our simple assumption of no eddy or water turbulence. The recent experimental progress presented here is a conceptual framework within which the asphalt surface properties employed technique from [15] and [14] spreading experiments for adhesion of oil [19] [20] [21] could be understood and evaluated. The oil standards meets the API of 1982 and of ASTM [22] [23] The relationship between experiment and theory is reviewed, and finally developed predictive models that could describe the spreading rate of Nigerian crude oil spill on sea waters. The procedure uses the properties of oil in relation to surface tension of water to develop a model to predict the spreading rate of Nigerian oil on water.

\section{Methodology for Model Development}

First, Crude oil sample were collected from Nembe Creek, this sample was used to develop the spread rate model, and the model was tested for validated with crude oil from Egbama, Forcados and Qua Iboe. The interfacial interactions were assumptions made in the model development are that the spreading rate of crude oil will be affected by the specific gravity (SG), interfacial tension and pour point properties of the crude oil. It was assumed that there will be interactions among these crude oil properties and there will be interaction between the crude oil and the temperature of water. Turbulence and ocean current were assumed constant to enable accurate examination of the effect of the oil properties on the spreading rate of the crude oil on water.

$2^{4}$ full factorial experiments were conducted to measure, the low and high levels of the factors affecting spread rate respectively. The levels of the four factors are listed in standard order in the columns temperature $\left(X_{1}\right)$ surface tension $\left(X_{2}\right)$ viscosity $\left(X_{3}\right)$ and specific gravity $\left(X_{4}\right)$ in Table 1 . To obtain the right model equation, the experiment proceeded with temperature measurement which started with a low level until you reach row (run) $2 \mathrm{k}$; the column for surface tension started with two low values of the surface tension parameter and it will be alternated in signs in blocks of 2 until row $2 \mathrm{k}$ is reached; and column viscosity started with $2^{2}=4$ at low values of specific gravity and the values were alternated in blocks of 8 . The sequence of high and low levels in the measurements was done to combine the observations to get the main effects and the interactions between the crude oil properties. The first experimental run puts all four factors affecting spreading rate at their low levels; the second experimental runs run sets factor low values of temperature and sets at high level and factors surface tension, viscosity, and specific gravity at low levels. Since the experimental designs have this property for fitting a regression model it is therefore an orthogonal designs. Standard methods were used for the determination of surface tension, specific gravity and the dynamic viscosity provided by [22] [23] the interactions were explained with reference to definitions from [24]. 
Table 1. Measured data for nembe creek crude oil.

\begin{tabular}{ccccccccc}
\hline Tab & $\begin{array}{c}\text { Temp } \\
\left({ }^{\circ} \mathrm{C}\right)\end{array}$ & $\begin{array}{c}\mathrm{ST} \\
(\mathrm{mN} / \mathrm{mR})\end{array}$ & $\begin{array}{c}\mathrm{DV} \\
\left(\mathrm{mm}^{2} / \mathrm{s}\right)\end{array}$ & SG & \multicolumn{2}{c}{ Rate of Spread $(\mathrm{R}), \mathrm{cm} / \mathrm{s}$} & $\begin{array}{c}\text { Mean R, } \\
(\mathrm{cm} / \mathrm{s})\end{array}$ \\
\hline 1 & 20.0 & 0.0594 & 8.13 & 1.2001 & $\mathrm{I}$ & $\mathrm{II}$ & $\mathrm{III}$ & 2.0830 \\
2 & 25.0 & 0.0481 & 7.02 & 0.9505 & 2.0820 & 2.0831 & 2.0839 & 2.4932 \\
3 & 30.0 & 0.0409 & 6.43 & 0.9101 & 2.4920 & 2.4935 & 2.4941 & 2.7607 \\
4 & 35.0 & 0.0378 & 5.23 & 0.8823 & 2.7606 & 2.7605 & 2.7610 & 3.1908 \\
5 & 37.5 & 0.0363 & 4.99 & 0.8717 & 3.1906 & 3.1903 & 3.1910 & 3.3528 \\
6 & 40.0 & 0.0348 & 4.75 & 0.8611 & 3.3527 & 3.3526 & 3.3531 & 3.5148 \\
7 & 42.5 & 0.0342 & 4.38 & 0.7860 & 3.5147 & 3.5150 & 3.514 & 3.7988 \\
8 & 45.0 & 0.0335 & 4.01 & 0.7109 & 3.7990 & 3.7988 & 3.7986 & 4.0827 \\
9 & 47.5 & 0.0326 & 3.58 & 0.6905 & 4.0830 & 4.0826 & 4.0825 & 4.9479 \\
10 & 50.0 & 0.0316 & 3.14 & 0.6701 & 4.9478 & 4.9479 & 4.9480 & 5.8131 \\
11 & 52.5 & 0.0303 & 3.07 & 0.5601 & 5.8132 & 5.8134 & 5.8127 & 6.8204 \\
12 & 55.0 & 0.0289 & 3.00 & 0.4501 & 6.8201 & 6.8206 & 6.8205 & 7.8277 \\
13 & 57.5 & 0.0192 & 2.95 & 0.3636 & 7.8278 & 7.8275 & 7.8275 & 8.7962 \\
14 & 60.0 & 0.0094 & 2.90 & 0.2771 & 8.7960 & 8.7961 & 8.7965 & 9.7646 \\
15 & 62.5 & 0.0053 & 2.45 & 0.1956 & 9.7650 & 9.7645 & 9.7643 & 10.6788 \\
16 & 65.0 & 0.0011 & 1.99 & 0.1141 & 10.6785 & 10.6789 & 10.6790 & 11.5930 \\
\hline & & & & & & &
\end{tabular}

Key: $\mathrm{ST}$ = surface tension, DV = dynamic viscosity, $\mathrm{SG}=$ specific gravity.

\section{Results and Discussion}

Orthogonal designs minimize the variance of the regression coefficients and provide equal precision of estimation in all directions.

A 4-variable, 2-level factorial design was carried out and was used to analyse the rate of spread of crude being modelled. The $2^{4}$ factorial designs were used to estimate the fifteen effects indicated in the linear model. That is, with 4 variables coded as $X_{1}, X_{2}, X_{3}$, and $X_{4}$; a 16-run experiment permits unique solutions for the coefficients (parameters) of the equation or linear model Equation (2).

$$
\begin{aligned}
R= & b_{0}+b_{1} X_{1}+b_{2} X_{2}+b_{3} X_{3}+b_{4} X_{4}+b_{12} X_{12}+b_{13} X_{13}+b_{14} X_{14}+b_{23} X_{23}+b_{24} X_{24} \\
& +b_{34} X_{34}+b_{123} X_{123}+b_{124} X_{124}+b_{134} X_{134}+b_{234} X_{234}+b_{1234} X_{1234}+e_{i}
\end{aligned}
$$

where: $R=$ rate of spreading of crude oil that is being modelled; $b s=$ regression coefficients of the model; $X s=$ coded variables; $e_{i}=$ random error with zero mean and constant variance. It measures the discrepancy in the functional relationship between the response and regression variables.

The oil properties are represented in the model of the Nembe Creek as $X_{1}$ to $X_{4}$ given that:

$X_{1}=$ Temperature $(\mathrm{T})\left({ }^{\circ} \mathrm{C}\right), X_{2}=$ surface tension $\mathrm{ST}, \mathrm{mN} / \mathrm{m}, X_{3}=$ dynamic viscosity (DV) $\mathrm{mm}^{2} / \mathrm{s}, X_{4}=$ specific gravity. $R=$ spreading rate $\mathrm{cm} / \mathrm{s}$. the predicted values of $R$ at the 16 points in the design were generated using combination of factorial 2 by 4 . The mean experimental observation $R$, the predicted $(\check{R})$. 


\section{The Spreading Rate Model for Nembe Creek Oil}

The spreading rate data for Nembe creek oil are presented in Table 1. The spreading rate gives Equation (3) is the dispersion measured experimentally for all the 15 run

$$
\sum_{u=1}^{16} S_{u}^{2}=3.91 \times 10 E-06
$$

where subscript $\mathrm{u}$ and $\mathrm{y}$ are counter, $N$ is total number of run, $S_{u}^{2}=$ maximum staistical dispersion is Equation (4)

$$
S_{y}^{2}=\frac{1}{N} \sum_{u=1}^{N} S_{u}^{2}
$$

The $G$-criteria treatment was performed on the data to give $G_{c a l}=0.2992$. This calculated $G$-value was compared with an $G$-value at 0.05 table $G_{(0.05,2,16)}=0.3222$ since $G_{c a l}<G_{t a b}$, the homogeneity condition was fulfilled, therefore regression analysis was carried out. Since the experimental design was orthogonal, the regression coefficient were estimated using experimental data of Table 1. After calculating the 16 effects using $b_{i j}=\frac{1}{N} \sum_{u=1}^{N} x_{i j} R_{u}$, their statistical significance was tested by constructing confidence intervals with $C_{i}=b^{\prime} s+t_{[\alpha, N(r-1)]} b^{\prime} s S_{b^{\prime} s}$. Where $S_{b^{\prime} s}$ is the estimated standard error in the regression coefficient (the $\left.b^{\prime} s\right), t_{[\alpha, N(r-1)] b^{\prime} s}$ is the appropriate tabulated $t$-criteria with $N(r-1)$ degrees of freedom in which $\alpha$ is p-value of $5 \%$ significance level was adapted. Testing hypothesis about each regression coefficient. Confidence interval for the regression coefficient are of the general form given as $C_{i}=b^{\prime} s+t_{[\alpha, N(r-1)] b^{\prime} s} S_{b^{\prime} s}$. From statistical tables, $t_{(0.05,2,32)}=1.694$ applying treatment equations, the error in each regression coefficient is $S_{b}=0.0000714$ and $\Delta b s=0.000121$. The $t$-values for testing significance of each regression coefficient were estimated. The summary of the estimated effects, the confidence intervals and the calculated $t$-values are presented in Table 2. Comparing each of the calculated $t$-value (Table 2) with the appropriate critical table value (1.694) shows that the entire regression coefficient is statistically significant. Therefore the model of the Nembe Creek is provided in Equation (5)

$$
\begin{aligned}
R= & 5.7199+0.3151 X_{1}+0.6242 X_{2}+1.2278 X_{3}+2.5603 X_{4}+0.0144 X_{12} \\
& -0.024 X_{13}+0.1543 X_{14}-0.0336 X_{23}+0.3256 X_{24}+0.7001 X_{34} \\
& -0.0059 X_{123}+0.004 X_{124}+0.0253 X_{134}+0.0122 X_{234}-0.0186 X_{1234}
\end{aligned}
$$

This model was validated with oil samples from Egbama, Forcados and Qua Iboe as presented in Figure 1. The model shows a clear prediction of the spreading rate of the three oils with a negligible factor of 0.0002 in magnitude.

Figure 2 presents the interactions of the interfacial tension, viscosity and the specific properties of the crude oils and Specific Gravity. The interaction effect of interfacial tension, viscosity and specific gravity is $0.0122 \mathrm{~cm} / \mathrm{s}$. This means that increasing simultaneously the interfacial tension, dynamic viscosity and specific gravity from their low levels to their high levels will increase the spreading rate of the crude oil by $0.0122 \mathrm{~cm} / \mathrm{s}$. This is explained by the positive sign against the 
coefficient of the interaction between these three factors $\left(b_{234}=0.0122\right)$. The interaction effect is however small compared to the main effect of the interacting factors. The interaction effect of temperature, surface tension, dynamic viscosity and specific gravity is -0.0186 . This means that increasing simultaneously the four factors from their low levels to their high levels will lead to a decrease in the spreading rate of the crude oil by $0.0186 \mathrm{~cm} / \mathrm{s}$. This is explained by the negative sign against the coefficient of the interaction between the four factors $\left(b_{1234}=\right.$ $-0.0186)$. The synergistic interaction showing their influence on the spreading rate of crude oil was evidently inversely related with temperature.

Table 2. Measured data for nembe creek crude oil.

\begin{tabular}{cccc}
\hline Regression Coefficient & Estimated Effect & Confidence Interval & t-values \\
\hline b0 & 5.7199 & \pm 0.000121 & $80,110.6$ \\
b1 & 0.3151 & \pm 0.000121 & 4413.17 \\
b2 & 0.6242 & \pm 0.000121 & 8742.30 \\
b3 & 1.2278 & \pm 0.000121 & $17,196.08$ \\
b4 & 2.5603 & \pm 0.000121 & $35,858.54$ \\
b12 & 0.0144 & \pm 0.000121 & 201.68 \\
b13 & -0.0240 & \pm 0.000121 & 336.13 \\
b14 & 0.1543 & \pm 0.000121 & 2161.06 \\
b23 & -0.0336 & \pm 0.000121 & 470.59 \\
b24 & 0.3256 & \pm 0.000121 & 4560.22 \\
b34 & 0.7001 & \pm 0.000121 & 9805.32 \\
b123 & -0.0059 & \pm 0.000121 & 82.63 \\
b124 & 0.0040 & \pm 0.000121 & 560.02 \\
b134 & 0.0253 & \pm 0.000121 & 354.34 \\
b234 & 0.0122 & \pm 0.000121 & 170.87 \\
b1234 & -0.0186 & \pm 0.000121 & 260.50 \\
\hline & & & 56.02 \\
\hline
\end{tabular}

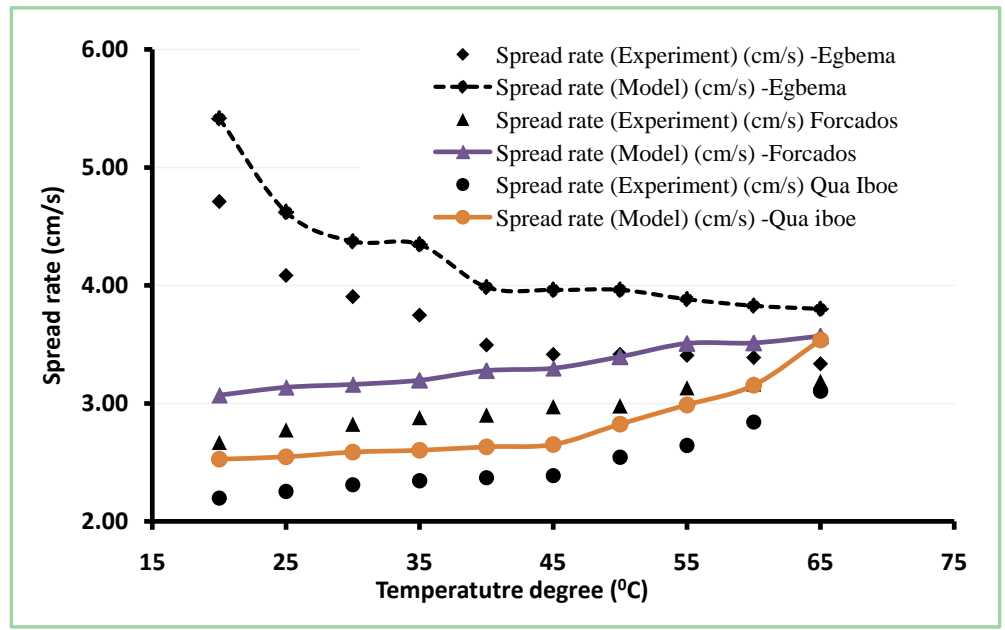

Figure 1. Spreading rate model of the Nembe Creek validated with crude oil from Egbama, Forcados and Qua Iboe. 


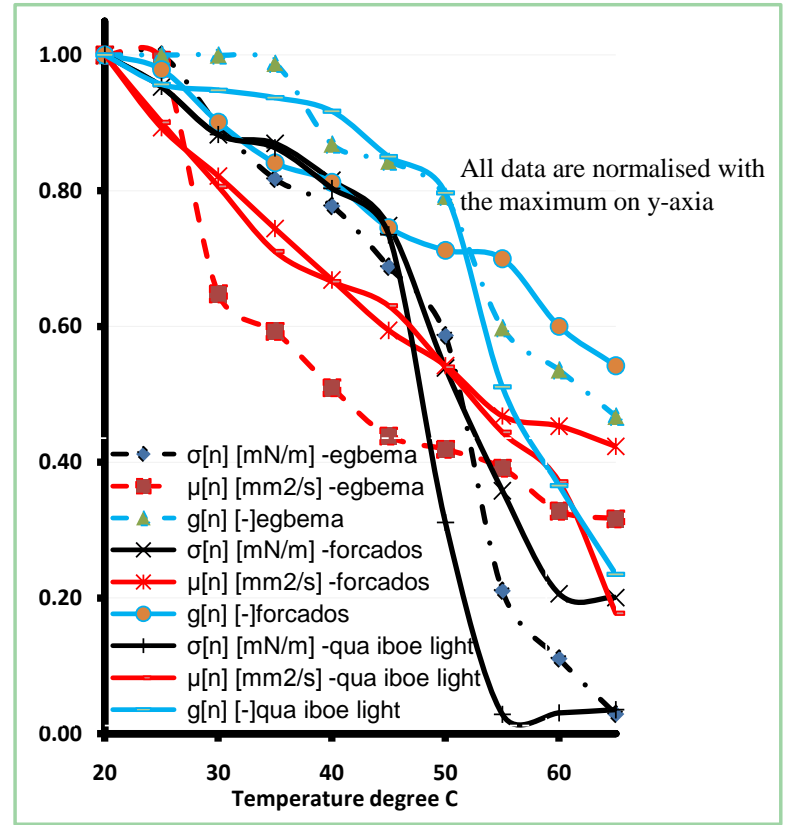

Figure 2. The interactive trend of the interfacial tension $(\sigma)$, viscosity $(\mu)$ and specific gravity $(g)$ of forcados, egbama and qua ibo oil.

\section{1) Viscosity}

The pour point property of the oil is probably the first influencing the spreading rate of the oil. Immediately the oil was spilled on the water, the oil quickly assumes the water temperature, this sets the spread rate to allow value. At $20^{\circ} \mathrm{C}$ when the water temperature was set at low, at low water temperature, the spreading rate value retarded, as the water temperature increases, the spreading rate value increases. Therefore our algorithm was reliable as the spreading rate followed an inverse relationship with the pour point values. This oil property is affected by temperature at Figure 3. It also influences the surface tension and specific gravity.

\section{2) Surface Tension}

Spherical pattern of thin layer of oil was seen immediately the oil came in contact with the water. This is because the gravity effect repelled the oil from stagnancy. Rather a pull of gravity caused a down spread of the oil. The net surface tension recorded were low values of $1.1136 \mathrm{mN} / \mathrm{m}$ at $20^{\circ} \mathrm{C}$ and $0.0325 \mathrm{mN} / \mathrm{m}$ at very high water temperature of $60^{\circ} \mathrm{C}$. The net surface tension was regarded as the spreading coefficient and was obtained as the value left after a total value of air/oil surface tension was summed to the interfacial oil/water surface and the air/water surface tension was subtracted the spreading rate of the observed at the same surface tension of $0.9988 \times 10 \mathrm{mN} / \mathrm{m}$ at $30^{\circ} \mathrm{C}$ and $1.1136 \mathrm{mN} / \mathrm{m}$ at $20^{\circ} \mathrm{C}$ was $4.3722 \mathrm{~cm} / \mathrm{s}$ and $5.4159 \mathrm{~cm} / \mathrm{s}$ having a corresponding density of 0.9999 and 0.4675 . The spreading rates were very close with same magnitude even at the large difference of densities of the oil. This is a clear indication that interfacial tension was a major factor which determines the extent of spread on water. As a large density difference did not affect the magnitude of the spreading rate. 


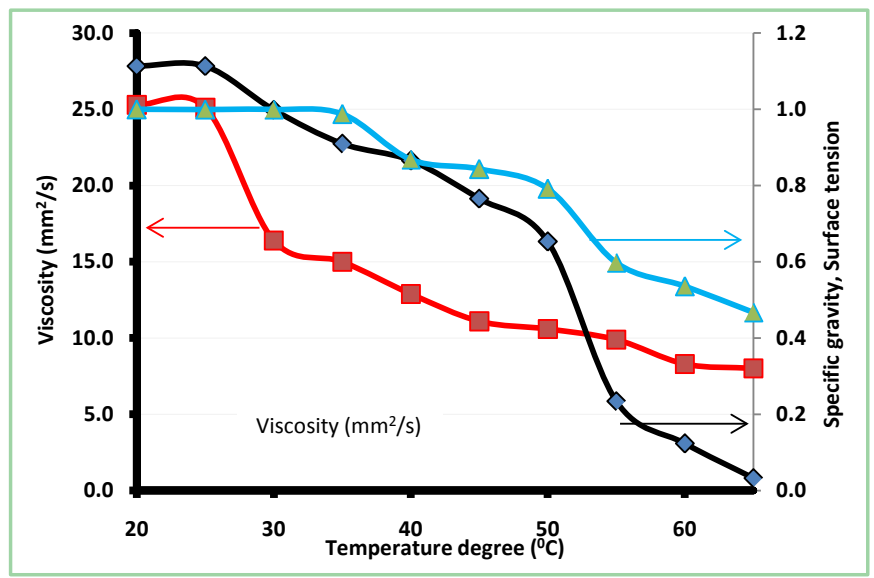

Figure 3. The interactive trend of the surface tension $(\sigma)$, viscosity $(\mu)$ and specific gravity $(g)$ at typical temperature.

\section{3) Density}

The density had a role to play when a longer time is allowed for the oil to spread. An extended experimental time gives a factor of 2.5 between the spreading rate values of both samples. Therefore, the spreading process was observed to have proceeded via two major steps. First at oil water contacts, gravity takes effects and the oil spreads out in a spherical or curved edge thin continuous manner. Secondly, the interfacial tension takes effect for a long time and ends with density effect. These two processes agrees with the work of [25].

\section{Conclusion}

The regression model presented here is expected to provide a practical solution to oil spill responses as well as remediation action to be taken. It is hoped to be applicable to continuous use for in-situ monitoring of the inherent spreading rates of oil spills on sea. Moreover, such surface spreading properties constitute the requisite input data for modelling the spreading rate of oil spill. The rate of spread of crude oil is dependent on density, viscosity and surface tension properties of the oil. Crude oil can form slicks and can have consequential impacts on aquatic in exposed ecosystems. These effects are due to the chemical composition at the time of oil water interaction with aquatic life as well as the extent in the local area of the oil spillage. When specific gravity, viscosity and interfacial tensions are low, oil slicks usually spread faster covering larger area therefore a quick response to arrest the damage can be initiated easily with the knowledge of the predictions equations are an exception to the prescribed.

\section{Acknowledgements}

The Petroleum Technology Development Fund (PTDF), Nigeria is acknowledged for sponsorship.

\section{Conflicts of Interest}

The authors declare no conflicts of interest regarding the publication of this paper. 


\section{References}

[1] Steyn, P. (2009) Oil Exploration in Colonial Nigeria, c. 1903-58. The Journal of Imperial and Commonwealth History, 37, 249-274. https://doi.org/10.1080/03086530903010376

[2] Hu, Deng, Y., Wang, D., Yang, H., Lv, D. and Kang, K. (2019) Hydrocarbon Accumulation Conditions and Key Exploration and Development Technologies for PL 19-3 Oilfield. Petroleum Research, 4, 29-51. https://doi.org/10.1016/j.ptlrs.2019.01.003

[3] Adesina (2002) Guardian Newspaper, Lagos Nigeria, Tuesday August 20, Oil Spill in Niger Delta Area. 1, 20.

[4] Jurgen Jonzen, SPDC Corporate Pipeline Asset Manager. http://news.nationalpost.com/2013/04/05/oil-spills-from-oil-thieves-and-shell-oper ational-failures-in-niger-delta-nigeria

[5] Abia, D. (2019) Nigeria: Threats of litigation Mount against Shell over the Recent Oil Spill in Gokana.

https://www.business-humanrights.org/en/nigeria-threats-of-litigation-mount-agai nst-shell-over-the-recent-oil-spill-in-gokana

[6] Vethamony, P., Sudheesh, K., Babu, M.T., Jayakumar, S., Manimurali, R., Saran, A.K., Srivastava, M., et al. (2007) Trajectory of an Oil Spill off Goa, Eastern Arabian Sea: Field Observations and Simulations. Environmental Pollution, 148, 438-444. https://doi.org/10.1016/j.envpol.2006.12.017

[7] Camp, D.W. and Berg, J.C. (1987) The Spreading of Oil on Water in the Surface Tension Regime. Journal of Fluid Mechanics, 184, 445-462. https://doi.org/10.1017/S0022112087002969

[8] Critchell, K., Grech, A., Schlaefer, J., Andutta, F.P., Lambrechts, J., Wolanski, E. and Hamann, M. (2015) Modelling the Fate of Marine Debris along a Complex Shoreline: Lessons from the Great Barrier Reef. Estuarine, Coastal and Shelf Science, 167, 414-426. https://doi.org/10.1016/j.ecss.2015.10.018

[9] Berry, A., Dabrowski, T. and Lyons, K. (2012) The Oil Spill Model OILTRANS and Its Application to the Celtic Sea. Marine Pollution Bulletin, 64, 2489-2501. https://doi.org/10.1016/j.marpolbul.2012.07.036

[10] Sebastiao, P. and Soares, C.G. (1995) Modeling the Fate of Oil Spills at Sea. Spill Science \& Technology Bulletin, 2, 121-131. https://doi.org/10.1016/S1353-2561(96)00009-6

[11] Njobuenwu, D. and Abowei, M. (2000) Spreading Rate of Crude Oil on Placid Aquatic Medium. Leonardo Journal of Sciences, No. 12, 11-24.

[12] Kamal, M.S., Hussein, I.A. and Sultan, A.S. (2017) Review on Surfactant Flooding: Phase Behavior, Retention, IFT, and Field Applications. Energy \& Fuels, 31, 7701-7720. https://doi.org/10.1021/acs.energyfuels.7b00353

[13] Bellino, P.W., Flynn, M.R. and Rangwala, A.S. (2013) A Study of Spreading of Crude Oil in an Ice Channel. Journal of Loss Prevention in the Process Industries, 26, 558-561. https://doi.org/10.1016/j.jlp.2012.07.001

[14] Hunter, K.A. and Liss, P.S. (1981) Organic Sea Surface Films. In: Duursma, E.K. and Dawson, R., Eds., Marine Organic Chemistry, Elsevier, New York, 259-298. https://doi.org/10.1016/S0422-9894(08)70331-3

[15] Bauget, F., Langevin, D. and Lenormand, R. (2001) Dynamic Surface Properties of Asphaltenes and Resins at the Oil-Water Interface. Journal of Colloid and Interface Science, 239, 501-508. https://doi.org/10.1006/jcis.2001.7566 
[16] Craster, R.V. and Matar, O.K. (2006) On the Dynamics of Liquid Lenses. Journal of Colloid and Interface Science, 303, 503-516. https://doi.org/10.1016/j.jcis.2006.08.009

[17] Adamson, A.W. and Gast, A.P. (1997) Physical Chemistry of Surfaces. John Wiley and Sons, Hoboken, 808.

[18] Raffa, P., Broekhuis, A.A. and Picchioni, F. (2016) Polymeric Surfactants for Enhanced Oil Recovery: A Review. Journal of Petroleum Science and Engineering, 145, 723-733. https://doi.org/10.1016/j.petrol.2016.07.007

[19] Jokuty, P., Whiticar, S., Wang, Z., Fingas, M., Lambert, V., Fieldhouse, B. and Mullin, J. (2008) A Catalogue of Crude Oil and Oil Product Properties. Emergencies Science Division, Environment Canada, Ottawa, Whiticar Scientific, Ottawa, United States Minerals Management Service, Department of the Interior, Herndon.

[20] Jokuty, P., Whiticar, S., McRoberts, K. and Mullin, J.A. (1996) Oil Adhesion Testing-Recent Results. Proceedings of the 19th Arctic and Marine Oil Spill Program Technical Seminar, Environment Canada, Ottawa, 9-27.

[21] Jokuty, P., Fingas, M.F., Whiticar, S. and Fieldhouse, B. (1995) A Study of Viscosity and Interfacial Tension of Oils and Emulsions. Environment Canada Manuscript Report Number EE-153, Ottawa, 50 p.

[22] API American Petroleum Institute (1982) Petroleum Measurement Tables Volume XI/XII. American Society for Testing and Materials, Philadelphia.

[23] Standard ASTM (1996) Annual Book of ASTM Standards-Section 5 Petroleum Products. Lubricants, and Fossil Fuels, American Society for Testing and Materials, West Conshohocken.

[24] Robert, H., Perry Don, W. and Green, W. (2000) Perry Chemical Engineering Handbook. CD ROM Version 3.0.1 of Adobe Acrobat.

[25] Wang, S.D., Shen, Y.M. and Zheng, Y.H. (2005) Two-Dimensional Numerical Simulation for Transport and Fate of Oil Spills in Seas. Ocean Engineering, 32, 1556-1571. https://doi.org/10.1016/j.oceaneng.2004.12.010 